\title{
Effects of Peers and Rank on Cognition, Preferences, and
}

\author{
Personality $^{*}$
}

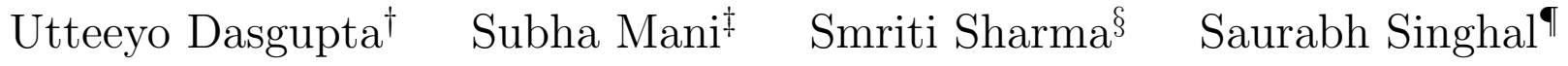

August 2020

\begin{abstract}
We exploit the variation in admission cutoffs across colleges at a leading Indian university to estimate the causal effects of enrolling in a selective college on cognitive attainment, economic preferences, and Big Five personality traits. Using a regression discontinuity design, we find that enrolling in a selective college improves university exam scores of the marginally admitted females, and makes them less overconfident and less risk averse, while males in selective colleges experience a decline in extraversion

\footnotetext{
${ }^{*}$ We thank Kehinde Ajayi, Felipe Barrera-Osorio, Leah Boustan, Matias Busso, Raissa Fabregas, Arya Gaduh, Ingo Isphording, Asim Khwaja, David McKenzie, Abhijeet Singh, Bertil Tungodden, Lore Vandewalle, and three anonymous reviewers for useful feedback. We also thank seminar participants at Copenhagen, Choice Lab, UPenn, Columbia, Fordham, GeorgiaTech, Hunter, UConn, 3ie, Indian School of Business, Monash, Rutgers, Shiv Nadar, and conference participants at NEUDC, IGC-ISI India Conference, ASSA, Leuven, York, and Nordic Conference in Development Economics for comments. We are grateful to the staff at colleges of University of Delhi for lending their support. Neha Agarwal, Riju Bafna, Piyush Bhadani, Tanya Gupta, Aishwarya Joshi, Japneet Kaur, and Anshul Yadav provided excellent research assistance. We acknowledge support from Fordham University, International Growth Center - India Central, UNU-WIDER, and Newcastle University. These institutions had no involvement in study design, data collection, analysis, or interpretation. This paper was previously circulated as "Cognitive, Socioemotional and Behavioral Returns to College Quality".

$\dagger$ utteeyodasgupta@gmail.com; Wagner College, Fordham University \& IZA.

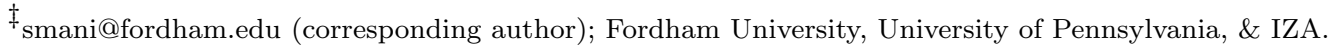

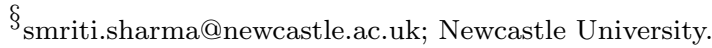

ๆs.singhal1@lancaster.ac.uk; Lancaster University \& IZA.
} 
Review of Economics and Statistics Just Accepted MS.

https://doi.org/10.1162/rest_a_00966

(C) 2020 UNU-WIDER. Published under a Creative Commons Attribution 4.0 International (CC BY 4.0) license.

and conscientiousness. We find differences in peer quality and rank concerns to be driving our findings.

Keywords: College Quality, Peer Effects, Rank Concerns, Regression Discontinuity, India

JEL Classification: I21, I26, C9, J24 
Review of Economics and Statistics Just Accepted MS.

https://doi.org/10.1162/rest_a_00966

(C) 2020 UNU-WIDER. Published under a Creative Commons Attribution 4.0 International (CC BY 4.0) license.

\section{Introduction}

Cognitive ability, completed years of schooling, and test scores have long been considered important determinants of success in life (Hanushek \& Woessmann, 2008; Oreopoulos \& Salvanes, 2011). However, there is now increasing evidence that suggests economic preferences and socioemotional traits like self-control, risk appetite, and competitiveness to be as important in determining educational attainment, labor market outcomes, and overall well-being (Almlund et al., 2011; Buser et al., 2014; Jaeger et al., 2010).

College is an important milestone that is believed to develop both cognitive and socioemotional aspects of an individual's human capital. Consequently, there is great emphasis on enrolling in selective colleges that are expected to provide high-achieving peers, better teachers, stronger alumni networks, and serve as a signal for higher ability. Experiencing such an environment for 3-4 years is likely to shape one's broader skill set. The existing literature on school and college quality reports both positive and non-significant effects of exposure to more selective educational institutions on academic outcomes (e.g., Abdulkadiroğlu et al., 2014; Ajayi, 2014; Jackson, 2010; Lucas \& Mbiti, 2014; Pop-Eleches \& Urquiola, 2013; Saavedra 2009; Sekhri, 2020). Interestingly, it remains mostly silent on the accompanying behavioral responses and underlying mechanisms that may explain these mixed results. For instance, being in a more selective educational institution can also present a challenge

for students who have a low ordinal rank relative to their peers. Students' perceptions of self-abilities based on relative rank could lead to behavioral responses that may dilute or negate the overall gains from attending a more selective educational institution (Elsner \& Isphording, 2017; Murphy \& Weinhardt, 2020; Pop-Eleches \& Urquiola, 2013).

The objective of this paper is to examine the returns from exposure to a selective college on academic outcomes, as well as on measures of risk taking, competitiveness, overconfidence, 
Review of Economics and Statistics Just Accepted MS.

https://doi.org/10.1162/rest_a_00966

(C) 2020 UNU-WIDER. Published under a Creative Commons Attribution 4.0 International (CC BY 4.0) license.

and Big Five personality traits 1 To the best of our knowledge, this is the first paper in the literature to causally identify the effects of enrolling in a more selective college on socioemotional and behavioral aspects of human capital accumulation. In doing so, we use rich student-level data in a regression discontinuity design to address the selection problem arising from sorting, i.e., high-achieving students self-select into more selective colleges while low-achieving students sort into less selective colleges.

We analyze data from the University of Delhi (DU), one of the top public universities in India, to estimate the returns to college quality across a range of colleges with varying levels of selectivity that are all within the same educational context. Admission into colleges within the DU system is based on the incoming cohorts' average scores on the high school exit exam. This gives rise to college-discipline-specific admission cutoffs that determine an individual's eligibility to enroll in a specific discipline in a college. We exploit students' inability to manipulate this admission cutoff, and compare outcomes of students just above the cutoff to those just below the cutoff to estimate the causal impact of enrolling in a more selective college.

Value-added models of learning will predict better academic and non-academic outcomes for students just above the cutoff enrolled in more selective colleges. The company of more able peers can allow richer learning opportunities, provide a more dynamic environment for group interactions and serve as a motivation to work harder to keep up with the competition (Jain \& Kapoor, 2015; Feld \& Zölitz, 2017). However, the marginal students, i.e., those just above the cutoff are also the worst-off relative to their peer group ('small fish in a big pond'), while

\footnotetext{
${ }^{1}$ That personality is malleable in adolescence and young adulthood is now well accepted (Borghans et al., 2008; Specht et al., 2011). While cognitive ability, typically measured by IQ, is relatively stable after age 10, there is evidence that negative and positive experiences can impact behavior and personality (e.g., Chuang \& Schechter, 2015; Schurer et al., 2018). A recent literature finds that socioemotional skills measured after varying lengths of program exposure (8-36 months), can in fact be shaped by soft skills interventions (e.g., Acevedo et al., 2017; Adhvaryu et al., 2018; Campos et al., 2017).
} 
Review of Economics and Statistics Just Accepted MS.

https://doi.org/10.1162/rest_a_00966

(C) 2020 UNU-WIDER. Published under a Creative Commons Attribution 4.0 International (CC BY 4.0) license.

those just below the cutoff are relatively better than their peers ('big fish in a small pond'). The marginally admitted student has a lower relative rank among her peer group that could lower her 'academic self-concept' resulting in a detrimental or zero impact on not just her future academic performance but also her behavior and personality (Marsh et al., 2008).2 Therefore, students above the cutoff face tradeoffs between the positive effects of higher ability peer environments and negative effects of low relative rank (Cicala et al., 2018; Elsner \& Isphording, 2017, 2018; Fabregas, 2018; Murphy \& Weinhardt, 2020). Consequently, the net effects of enrolling in a more selective college could go in either direction 3

We combine data from a series of incentivized tasks and socioeconomic surveys administered to over 2000 undergraduate students at different colleges of DU to examine the returns to enrollment in more selective college environments. The first outcome of interest is academic attainment as measured by scores on standardized university-level exams. Next, we examine impacts on economic preferences such as competitiveness, overconfidence, and risk elicited using incentivized tasks. The final set of outcomes deals with the Big Five traits (Openness to experience, Conscientiousness, Extraversion, Agreeableness, and Emotional stability), which is a broadly accepted taxonomy of personality traits

\footnotetext{
${ }^{2}$ The evidence on rank effects being more prevalent in more heterogeneous student ability environments is not conclusive. In the education psychology literature, Marsh et al. (2008) show that rank concerns are likely to prevail across different settings, and even in groups of gifted students. In economics, Elsner and Isphording (2017) find that ordinal rank concerns hold in cohorts with both high and low variance in ability. These results could also be linked to the literature on the effect of heterogeneity in peer ability on student achievement and effort, and the findings appear mixed. For example, Carrell et al. (2013) and Booij et al. (2017) find student achievement to be higher in low variance peer ability settings. On the other hand, Lyle (2009) finds that high variance in peer ability increases student achievement.

${ }^{3}$ This could also explain the mixed evidence on peer effects in education with some studies finding positive peer effects and others documenting non-linear or no effects (Sacerdote, 2011).

${ }^{4}$ These preferences and traits have been identified to explain a range of labor market outcomes. Competitiveness can explain gender gaps in wages (Niederle \& Vesterlund, 2007). Overconfidence affects entrepreneurial entry (Koellinger et al., 2007). Recent work from
} 
Review of Economics and Statistics Just Accepted MS.

https://doi.org/10.1162/rest_a_00966

(C) 2020 UNU-WIDER. Published under a Creative Commons Attribution 4.0 International (CC BY 4.0) license.

Several interesting findings emerge from our analysis. First, enrollment in a selective college leads to gains in scores on standardized university-level exams for marginally admitted females, and their higher attendance rates are possibly driving this effect. Second, exposure to more able peer environments in these selective colleges makes females less risk averse and less overconfident. Third, we find that marginally admitted males experience a significant decline in extraversion and conscientiousness as compared to their counterparts in less selective colleges, representing 'small fish in a big pond' effects. Fourth, we find suggestive evidence that the returns to enrolling in selective colleges vary by college quality, with males' personality traits being more susceptible to concerns over low relative ranks at the top end of the college quality distribution. Finally, we do not find significant variation in measures of teacher quality across colleges implying differences in peer quality and rank concerns to be driving our results.

Our findings are consistent with recent work on related topics. For instance, Murphy and Weinhardt (2020) exploit idiosyncratic variation in cohort composition among primary school children in the UK to find that students with the same ability but higher relative rank perform significantly better in secondary school. Applying a similar identification strategy to US data, Elsner and Isphording (2017) find that students with higher ordinal rank are more likely to complete high school and enter and graduate from college. Elsner and Isphording (2018) also find that low relative rank increases the likelihood of engaging in risky and developing countries also shows a link between these skills and indicators of labor force participation, performance, and skill accumulation (Dasgupta et al., 2015; Nordman et al., 2019; Sharma \& Tarp, 2018). Finally, a spate of recent papers also finds that soft skills embedded training programs can influence labor market performance (through effects on socioemotional traits). Adhvaryu et al. (2018) find an on-the-job soft skills training program for Indian female garment workers to have led to gains in worker productivity, possibly through improvements in extraversion and forward-looking behavior. Acevedo et al. (2017) find that a soft skills embedded vocational training resulted in higher levels of soft skills and higher employment for females in the Dominican Republic. Campos et al. (2017) find that a psychology-based personal initiative program for microenterprise owners in Togo led to higher profits and adoption of business practices. 
Review of Economics and Statistics Just Accepted MS.

https://doi.org/10.1162/rest_a_00966

(C) 2020 UNU-WIDER. Published under a Creative Commons Attribution 4.0 International (CC BY 4.0) license.

violent behavior, and they attribute this to diminished future expectations and perceived status arising from lower ordinal rank. Fabregas (2018) using data from Mexico City middle schools also finds that students who are just above the cutoff express lower perseverance and aspirations to attend college. Interestingly, the effects we observe for behavior and personality traits are larger than those for standardized university exam scores. This is in line with findings in Sacerdote (2011) wherein the peer effects in higher education are greater on social outcomes related to memberships in sorority/fraternity, smoking and drinking than on academic achievement. Overall, our findings contribute towards understanding the gender-differentiated cognitive and non-cognitive returns to post-secondary education.

The rest of the paper is organized as follows. The institutional setting and college admissions process at the University of Delhi, sampling strategy, and data are described in Section 2. The empirical strategy is outlined in Section 3. All results and robustness checks are presented in Section 4. Concluding remarks follow in Section 5.

\section{Background and Data}

University of Delhi (DU) is one of India's top public universities that offer three-year undergraduate education to approximately 160,000 full-time students. DU consists of 79 colleges, each offering degrees in multiple disciplines such as science, commerce, arts, and humanities. Each college is an independent entity such that it has its own campus, faculty, students, and teaching is conducted within the colleges. However, the curriculum and all exams for each discipline are determined centrally by DU and are identical across all colleges. Teacher salaries are also the same across colleges in DU. These are unique features of DU as in most settings, these factors vary across educational institutions. 
Review of Economics and Statistics Just Accepted MS.

https://doi.org/10.1162/rest_a_00966

(C) 2020 UNU-WIDER. Published under a Creative Commons Attribution 4.0 International (CC BY 4.0) license.

\subsection{College Admissions Process}

College admissions for most disciplines in DU are based on the student's high school exit exam score computed as the average of best of four out of five subjects, including language 5 In the first two weeks of June each year, students apply using a Common Pre-Admission Form where they state their high school exit exam scores, and select the colleges and the disciplines within the colleges they wish to apply to. The application costs INR 100 (approximately 1.5 USD). Further, this form can be purchased and submitted at multiple centers across Delhi, thereby minimizing any time costs arising from traveling to several colleges.

After the applications period is complete, based on capacity constraints and the incoming cohort's average score, each discipline within a college announces the cutoff scores that determine admission into the specific college and discipline ${ }^{6}$ All applicants above the cutoff in the discipline are eligible to take admission in the college-discipline. Since there is excess demand for high-quality colleges, the cutoffs for these colleges are significantly and systematically higher than the low-quality colleges. If there are vacancies, colleges announce a second list with lower cutoffs. This process continues for several rounds as colleges gradually lower their cutoffs until all spots are filled.7] As expected, the more selective colleges fill their seats within the first couple of rounds while the less selective ones sequentially lower their cutoffs, taking at times up to 10 rounds to fill their seats. As a result, the DU college admission pro-

${ }^{5}$ In India, after a common high-stakes exam in grade 10, in the last two years of high school, students select into one of the following academic tracks, each of which has four subjects and a language: science, commerce, and humanities. At the end of grade 12, they write the high school exit exam which varies by track. College admissions often require a certain high school track. For example, students applying for undergraduate degrees in science should have had a science track. Commerce and economics disciplines require applicants to have studied mathematics in their high school tracks.

${ }^{6}$ These cutoffs are publicly available at http://www.du .ac .in/index.php?id=664.

${ }^{7}$ As cutoffs drop between admission rounds, it is possible for students to move 'up' to colleges where they are now eligible. In our sample, $26.5 \%$ of the students switched colleges during the admission process, of which $94 \%$ moved to a more selective college. We discuss this further in Section 4.3 . 
Review of Economics and Statistics Just Accepted MS.

https://doi.org/10.1162/rest_a_00966

(C) 2020 UNU-WIDER. Published under a Creative Commons Attribution 4.0 International (CC BY 4.0) license.

cess creates an environment where students who enroll in more selective colleges are exposed to high-achieving peers as compared to students enrolled in less selective colleges.

\section{$2.2 \quad$ Sampling Strategy}

Our study was conducted during January-March 2014. We constructed our sample in the following manner. First, to ensure representativeness along the distribution of college quality, we obtained the list of all 79 colleges affiliated with DU. Second, we drew a list of 58 colleges that offer disciplines in commerce and/or economics 8 These 58 colleges can be further categorized into daytime coeducational colleges (32), daytime women-only colleges (17), and evening coeducational colleges (9). Of the 32 daytime coeducational colleges, we further exclude 7 colleges that offer too few disciplines or use any criteria other than high school exit exam scores for admissions, resulting in a list of 25 target colleges. After considering admission cutoffs for each of these 25 colleges for three years (2011-13) and budget constraints, we identified 18 colleges that had consistently ranked cutoffs across the three years for economics and commerce, of which we could implement our study in 15 colleges with varying cutoffs.

We focus on the two disciplines of economics and commerce for a number of reasons, in addition to cost considerations. First, enrollment in economics and commerce is usually higher than in most other disciplines. For example, in DU in 2011, the total enrolment in the first year for economics and commerce was over 10,200 students, accounting for $28 \%$ of total student intake for honors disciplines 9 Second, economics and commerce have higher

\footnotetext{
${ }^{8}$ The remaining 21 colleges offer only specialized disciplines such as pharmacy, nursing, homeopathy, physical and sports education, and art, etc.

${ }^{9} \mathrm{~A}$ concern with focusing on economics and commerce may be that of discipline-specific gender-based selection effects. Based on data obtained under the Right to Information Act, we calculate the share of female students across all colleges within DU enrolled in the first year in 2011 in a variety of disciplines (Table A1 in the Online Appendix). The share of females exceeds $50 \%$ in the arts disciplines and is just below $50 \%$ in the science disciplines.
} 
Review of Economics and Statistics Just Accepted MS.

https://doi.org/10.1162/rest_a_00966

(C) 2020 UNU-WIDER. Published under a Creative Commons Attribution 4.0 International (CC BY 4.0) license.

cutoffs across all colleges as compared to other popular disciplines such as history, political science, mathematics, and English. To illustrate, in our sample of 15 colleges, in 2011, the average cutoff for commerce and economics is $91 \%$. On the other hand, the average cutoffs for other disciplines are: history (74\%), political science (75.8\%), mathematics (82.8\%), and English (77.13\%). Third, and importantly, admissions into economics and commerce are based solely on high school exit exam scores, facilitating the regression discontinuity design, while for some other disciplines, the admission process entails a combination of written entrance exams, high school exit exam scores, and interviews.

We also examine whether colleges in our sample are representative of the remaining colleges in DU in terms of their selectivity. Figure A1 in the Online Appendix shows that the distribution of cutoffs in economics and commerce in our sample of 15 colleges are overlapping with those of the remaining 43 of the 58 colleges, and the Kolmogorov-Smirnov tests do not reject the null of equal distributions ( $\mathrm{p}$-value $=0.922$ and 0.941 for economics and commerce respectively), suggesting that our sample of colleges is representative of the remaining colleges in DU.

Further, a wealth of evidence suggests that colleges in DU are among the most favored choices for economics and commerce. India Today, a well-known Indian magazine, publishes an annual ranking of the top fifty colleges across the country for various disciplines. This list is based on a perceptions-based survey and factual survey. In 2011 and 2012 (the years of admission for the sample of students in our survey), for the categories of commerce and arts (economics falls within arts category), several colleges of DU feature in the top fifty colleges across India 10 Similarly, the National Institutional Ranking Framework (NIRF), a recent This is consistent with previous evidence in the literature on gender-based selection across disciplines (see Buser et al., 2014 and papers cited therein). Notably, we do not find the share of female students in economics and commerce to be outliers, implying that disciplinespecific selection effects at the time of entry into DU are unlikely to be a pressing concern for our analysis.

${ }^{10}$ The survey methodology is available at: https://www.indiatoday.in/india/ 
Review of Economics and Statistics Just Accepted MS.

https://doi.org/10.1162/rest_a_00966

(C) 2020 UNU-WIDER. Published under a Creative Commons Attribution 4.0 International (CC BY 4.0) license.

initiative by the Indian Ministry of Human Resource Development ranks higher education institutions across the country on a range of parameters. According to the latest data for 2019 for undergraduate programs in arts and commerce, eleven out of top twenty colleges are in DU 11

In the region of Delhi and neighboring states, DU is the leading university offering these nontechnical disciplines. Other public universities in the area offering similar disciplines are quite few, much smaller, and are not considered as reputable (Borker, 2017). Private universities are substantially more expensive than DU and not as competitive. In the NIRF, none of the other high-ranking colleges in Delhi are non-DU and no other high-ranking colleges are in close proximity of Delhi. It is also expensive to relocate to a different city, especially as most colleges have limited on-campus housing facilities $\left.{ }^{[2}\right]$ Further, nationally representative data such as the Indian Census and National Sample Surveys show that migration among youth is low for education and accounts for only a small share of the migrant stream. Most migrants move within-state (Chandrasekhar and Sharma, 2014). This suggests that among those who narrowly fail to get admitted into more selective DU colleges, a less selective college in DU is likely to be preferable to attending other universities in Delhi and surrounding states ${ }^{13}$ best-colleges/story/best-colleges-in-india-2012-methodology-105020-2012-06-08. 2011 rankings available at: https://www.indiatoday.in/bestcolleges/2012/ compare-college/2011-commerce-arts. 2012 rankings at: https://www.indiatoday. in/bestcolleges/2012/compare-college/2012-commerce-arts.

${ }^{11} \mathrm{NIRF} 2019$ rankings are available at https://www.nirfindia.org/2019/ CollegeRanking.html.

${ }^{12}$ Borker (2017) finds that $72 \%$ of DU students are from Delhi and live with their parents. In 2016, almost $80 \%$ of applicants to DU were from Delhi and the neighboring states of Uttar Pradesh and Haryana: https://www.hindustantimes. com/delhi/50-delhi-university-aspirants-from-delhi-this-year/ story-oWvwZH76uFK7DpgWP001CP.html.

${ }^{15}$ We conducted a survey of approx. 300 grade 12 students across 11 high schools in Delhi in 2019, to find that DU is the top choice for over $93.3 \%$ of them. 
Review of Economics and Statistics Just Accepted MS.

https://doi.org/10.1162/rest_a_00966

(C) 2020 UNU-WIDER. Published under a Creative Commons Attribution 4.0 International (CC BY 4.0) license.

\section{$2.3 \quad$ Data}

We collected data on approximately 2000 second and third year students enrolled in economics and commerce disciplines in these 15 colleges. To conduct the surveys during class hours, we obtained approval from the college principals, and collaborated with teachers at the 15 colleges to determine the specific session timings. Upon arriving in the classrooms, teachers introduced the research team, and students were told that we would be conducting a decision-making study and survey, that participation was voluntary, and that they would be monetarily compensated for their time.

In the first part of the study, we conducted incentivized experiments to elicit economic preferences. First, to capture subjects' competitiveness and overconfidence, we used a simple number-addition task (similar to Bartling et al., 2009). After a practice session, participants had to predict their performance in advance, and also choose between a piece-rate and tournament compensation scheme. Under the piece-rate scheme, INR 10 was paid for every correct answer. Under the tournament scheme, INR 20 was paid for every correct answer if the subject out-performed a randomly selected student of DU who had solved the questions earlier We define competitiveness as a dummy that takes a value 1 if the subject chose the tournament compensation scheme and 0 if the subject chose the piece-rate compensation scheme. As in Dasgupta et al. (2017), we define overconfidence as the ratio of the predicted performance to the student's performance in the actual task 15

Second, to measure risk preferences, we used the Gneezy and Potters (1997) investment task. In this, subjects allocated a portion of their endowment (INR 150) to a risky lottery

\footnotetext{
${ }^{14}$ We implemented a pilot version of this game where forty students from DU had participated, and their performance is used for comparison in the tournament wage scheme.

${ }^{15}$ Our measure of overconfidence falls in the category of overestimation (Moore and Healy, 2008). Our competition design as well as the non-incentivized belief elicitation is similar to Dasgupta et al. (2015), Dasgupta et al. (2017), and Kamas and Preston (2012). Further, since we were already paying for the real effort task, we did not incentivize the belief elicitation in line with Karni and Safra (1995).
} 
Review of Economics and Statistics Just Accepted MS.

https://doi.org/10.1162/rest_a_00966

(C) 2020 UNU-WIDER. Published under a Creative Commons Attribution 4.0 International (CC BY 4.0) license.

and set aside the remainder. If they won the lottery based on a roll of a dice, the invested amount was tripled and they also got any amount they set aside. Conversely, if they lost the lottery, they only received the amount that was set aside. We define risk preference as the proportion allocated to the risky lottery in the investment game.

In the second part of the study, we implemented a socioeconomic survey that collected details on family background characteristics, school and college information, academic performance, and participation in extra-curricular activities. To measure cognitive attainment, we collected data on standardized university exam scores ${ }^{16}$ To measure personality traits, we administered the 10-item Big Five inventory (Gosling et al., 2003) that consists of the following traits. Openness to experience captures a tendency to be open to new aesthetic, cultural, or intellectual experiences. Conscientiousness refers to a tendency to be organized, responsible, and hard working. Extraversion relates to an outward orientation of one's interests and energies oriented towards the outer world of people, characterized by sociability. Agreeableness is related to the tendency to act in a cooperative and unselfish manner. Emotional stability (opposite of Neuroticism) is predictability and consistency in emotional reactions with absence of rapid mood changes.

Overall, we conducted 60 sessions with approximately 35 subjects per session. Each session lasted about 75 minutes. No feedback was provided between or after the tasks. All subjects received a show-up fee of INR 150. The average additional payment was INR 230. All subjects participated only once in the study. To minimize wealth effects, additional payments were based on one of the randomly chosen incentivized tasks. Instructions for the incentivized tasks are available in Online Appendix B.

\footnotetext{
${ }^{16}$ We also administered a 10-item Raven's (progressive) matrices test, which is acknowledged as a measure of fluid intelligence (e.g., see review in Dean et al., 2019). We find a strong positive and significant relationship between performance on Raven's test and university exam scores ruling out concerns about these exams reflecting rote-learning skills alone. See Table A2 in the Online Appendix.
} 
Review of Economics and Statistics Just Accepted MS.

https://doi.org/10.1162/rest_a_00966

(C) 2020 UNU-WIDER. Published under a Creative Commons Attribution 4.0 International (CC BY 4.0) license.

\section{Empirical Specification and Sample Description}

\subsection{Empirical Specification}

For estimating the returns to college quality, we first group colleges based on their relative selectivity. We use admission cutoffs, as exogenously announced by the individual colleges, as the criteria to sort the 15 colleges in our sample into four ordered categories ranging from 1 (highest rank) to 4 (lowest rank). As a result, colleges with similar cutoffs appear under the same group/rank. In Table A3 in the Online Appendix, for each of the four ranks, we present the means and standard deviations of cutoffs within each rank. As expected, the average cutoffs are greater in the higher ranked colleges. Further, the cutoffs appear to show greater dispersion as one moves down the ranks. This is not surprising as less selective colleges are likely to have more heterogeneity than more selective colleges. A similar pattern emerges if we examine the means and standard deviations of high school exit exam scores within a rank. Overall, Table A3 shows that students who perform similarly in high school exit exams are grouped within each rank.

Next, for each rank we compute the minimum score required for admission into the group. These cutoffs vary by student type where students differ in their current discipline (commerce and economics), academic track in high school (science, commerce, and humanities), year of entry (2011 and 2012), and gender (male and female). For example, a student seeking admission into economics, having studied science in high school faces a different cutoff from a student who studied commerce in high school. Thus, for each rank of colleges we get a set of cutoffs that define the minimum score required by each student type for admission into that college rank.

We then combine the cutoffs, ranks, and student data. For our analysis, from an initial sample of approximately 2000 students we exclude all those students whose admissions were 
Review of Economics and Statistics Just Accepted MS.

https://doi.org/10.1162/rest_a_00966

(C) 2020 UNU-WIDER. Published under a Creative Commons Attribution 4.0 International (CC BY 4.0) license.

not based on their high school exit exam scores. This includes students belonging to historically disadvantaged backgrounds (Scheduled Castes, Scheduled Tribes, and Other Backward Classes) for whom affirmative action policies mandate a fixed number of seats (29.3\%); students admitted on the basis of excellence in sports or other extra-curricular activities (4.8\%); those who transferred across colleges after enrollment or switched disciplines within a college $(0.3 \%)$; and those providing insufficient information (1.3\%). These exclusions leave us with 1331 students.

Since we are interested in estimating the returns to enrollment in a more selective college group, we now construct three samples using our sample of 1331 students. In the first constructed sample, colleges in rank 1 are assigned to the treated group/more selective colleges and the remaining colleges (in ranks 2, 3, and 4) are assigned as comparison group/less selective colleges. In the next sample, colleges in ranks 1 and 2 are assigned to the treated group and the remaining colleges (in ranks 3 and 4) are assigned to the comparison group. Finally, a third sample is constructed where colleges ranked 1, 2, and 3 are assigned to the treated group and colleges in rank 4 are in the comparison group. Following Abdulkadiroğlu et al. (2014), Jackson (2010) and Pop-Eleches and Urquiola (2013), we construct our final analysis sample by 'stacking' the three samples together, and estimate a single average treatment effect measuring the impact of enrollment in a relatively selective college. The stacking method has two advantages. First, it allows us to estimate the effect of enrolling in a more selective college over the distribution of college quality. Second, this methodology increases the sample size and consequently power. Note that stacking our sample can plausibly make a student appear at most three times in the data. However, as we only use observations near the cutoff for our analysis (i.e., within a 5-percentage point window), it results in 868 students appearing more than once in the final analysis sample of 2393 observations.

Of course, enrollment in a more selective college is endogenous, as not all students who 
Review of Economics and Statistics Just Accepted MS.

https://doi.org/10.1162/rest_a_00966

(C) 2020 UNU-WIDER. Published under a Creative Commons Attribution 4.0 International (CC BY 4.0) license.

are eligible to enroll do so ${ }^{17}$ To account for this, we use a fuzzy regression discontinuity (RD) design where enrollment is instrumented by eligibility to enroll in a more selective college (Lee and Lemieux, 2010). In particular, we estimate the following set of instrumental variable (IV) regressions where the first-stage regression is:

$$
T R_{i j}=\alpha_{0}+\alpha_{1} T_{i j}+\alpha_{2} d_{i j}+\alpha_{3} d_{i j}^{2}+\alpha_{4} d_{i j} T_{i j}+\alpha_{5} d_{i j}^{2} T_{i j}+\sum_{l=6}^{K} \alpha_{l} X_{l i j}+\eta_{j}+\delta_{m}+\epsilon_{i j}
$$

and the corresponding second-stage regression is:

$$
Y_{i j}=\delta_{0}+\delta_{1} T R_{i j}+\delta_{2} d_{i j}+\delta_{3} d_{i j}^{2}+\delta_{4} d_{i j} T R_{i j}+\delta_{5} d_{i j}^{2} T R_{i j}+\sum_{l=6}^{K} \delta_{l} X_{l i j}+\eta_{j}+\delta_{m}+\mu_{i j}
$$

where $Y_{i j}$ in equation (2) is the outcome variable of interest for student $i$ of type $j$. Equation (11) is a linear probability model where $T R_{i j}$ takes the value 1 if student $i$ of type $j$ is treated, i.e., enrolled in a more selective college. The running variable, $d_{i j}$, is computed as the difference between student $i^{\prime} s$ high school exit exam score and the relevant college rank-specific cutoff faced by her type $j$. The instrument is a dummy variable for eligibility, $T_{i j}$, that takes a value 1 if $d_{i j}$ is non-negative, 0 otherwise. We allow for non-linearity in the relationship between the outcomes and the running variable by including a quadratic specification in the running variable as well as allow the returns from college quality to vary on each side of the cutoff by allowing interactions between the TR dummy and $d_{i}$ and $d_{i}^{2}$. Our regressions also include cutoff fixed effects $\left(\eta_{j}\right)$ where the cutoffs vary by student types. This allows us to obtain the relevant counterfactual for a student enrolled in the high-quality college - a student of the same type (i.e., currently enrolled in the same discipline, with the same high

${ }^{17}$ Similarly, we also have a few instances where students who are ineligible for a more selective college are admitted to that college. Overall, in the stacked sample used in the analysis, only $0.37 \%$ of the subjects who have a negative distance from the cutoff are enrolled in a more selective college, and approximately $8.85 \%$ of the subjects who have a positive distance from the cutoff are enrolled in a less selective college. 
Review of Economics and Statistics Just Accepted MS.

https://doi.org/10.1162/rest_a_00966

(C) 2020 UNU-WIDER. Published under a Creative Commons Attribution 4.0 International (CC BY 4.0) license.

school academic track, same gender, and same year of admission) who marginally missed the relevant cutoff. To account for variation in the timing of the surveys, we also include survey month fixed effects $\left(\delta_{m}\right)$. We also include a vector of predetermined characteristics $(X s)$ such as mother's education, father's education, private school enrollment, age, household income, and religion in the regressions, to improve the precision of our estimates. Finally, $\mu_{i j}$ and $\epsilon_{i j}$ are iid error terms.

The coefficient estimate on TR in equation (2) gives us the local average treatment effect (LATE) of being enrolled in a more selective college. As the literature on the effects of school and college quality documents significant heterogeneity by gender (e.g., Hastings et al., 2006; Jackson, 2010; Kling et al., 2005), we also report our results for males and females separately.

Since the running variable is discrete, following Lee and Card (2008), we cluster our standard errors with respect to 0.25 bins of the running variable ${ }^{18}$ The choice of the bandwidth is an important issue in $\mathrm{RD}$ analysis. Since we have various outcome variables, we fix the bandwidth to be 5 percentage points for the main analysis. In Section 4.3 , we show that our results are robust to using outcome-specific optimal bandwidths.

As we wish to estimate the effects of enrolling in a more selective college, the ideal sample would comprise students/DU applicants who strictly prefer more selective colleges to the less selective ones such that a score above (below) the relevant cutoff would lead to admission in a more (less) selective college. As explained in Section 2.1. DU follows a decentralized admission process wherein applicants fill in a common form to indicate the college-disciplines they wish to apply to 19 This process does not gather the preferences of the applicants

\footnotetext{
${ }^{18}$ The main results are robust to two-way clustering of the standard errors at student and bin level, as in Cameron et al. (2011). Results are available from the authors upon request.

${ }^{19}$ The student allocation mechanism in DU is different from the more commonly observed centralized mechanisms such as the Boston school choice mechanism (Abdulkadiroğlu et al., 2014), the student or college proposing deferred acceptance mechanisms, or the top trading
} 
Review of Economics and Statistics Just Accepted MS.

https://doi.org/10.1162/rest_a_00966

(C) 2020 UNU-WIDER. Published under a Creative Commons Attribution 4.0 International (CC BY 4.0) license.

over colleges and/or disciplines, and all we observe is the current college-discipline that the student is enrolled in, her high school exit exam score, and the cutoffs at the time of admission. Nonetheless, with a fixed supply of seats, the higher cutoffs at colleges are a reflection of excess demand for those seats. It is then reasonable to assume that the average student prefers admission into a college with higher cutoffs than one with lower cutoffs. We discuss this further in Section 4.3.

\subsection{Summary Statistics}

In Table 1, we present descriptive statistics for our sample. In Panel A, we see that average score on standardized university-level exams, our measure of academic attainment during college, is $70 \%$ with no significant gender differences. In Panel B, we summarize choices in the incentivized tasks: competitiveness, overconfidence, and risk. Thirty-one percent of the subjects are considered competitive as they choose the tournament payment scheme. The average student is overconfident as the ratio of the expected number of correct answers to the number correctly solved in the actual task is 1.6 , significantly higher than 1 . These findings are also supported by other papers that find that about one-third of subjects choose the tournament wage scheme, and often irrationally overestimate their own abilities (e.g., Dasgupta et al., 2015; Niederle \& Vesterlund, 2007). Finally, the average investment of $46.6 \%$ in the risky asset is in the range of $44.67-70.86 \%$ observed for student populations (Charness \& Viceisza, 2016). The significant gender differences in competitiveness and risk aversion are in accordance with previous work (see Niederle, 2016 for a review).

In Panel C, we summarize subjects' Big Five personality traits. Subjects report a higher score on agreeableness, conscientiousness, and openness to experience than they do for extraversion and emotional stability. Females are more extrovert, conscientious, and agreeable, and less cycle mechanism (Sönmez and Ünver, 2011), where students indicate preference rankings over disciplines and colleges and a central body allocates students. 
Review of Economics and Statistics Just Accepted MS.

https://doi.org/10.1162/rest_a_00966

(C) 2020 UNU-WIDER. Published under a Creative Commons Attribution 4.0 International (CC BY 4.0) license.

emotionally stable than males. Schmitt et al. (2008) note similar gender differences in personality traits across several cultural contexts. Finally, in Panel D, we present descriptive statistics on background characteristics. The average age of the students is close to 20. Over 90\% are Hindus (the dominant religion in India), $85 \%$ attended a private high school, and 75-78\% have either a highly educated mother or father (college degree or higher). A third of the sample comes from low-income households (those earning less than INR 50,000 per month or INR 600,000 per year) ${ }^{20}$

\subsection{Testing Validity of the RD Design}

The RD model relies on two assumptions: (a) there is no precise manipulation of the assignment variable around the cutoff, and (b) the probability of being enrolled in a more selective college is discontinuous at the cutoff.

Features of the DU admission process rule out manipulation related concerns. First, admission depends on scores on high school exit exams that follow a double-blind grading procedure, making manipulation difficult, if not outright impossible. Second, at the time of application to DU colleges, students are not aware of the precise cutoffs that will determine admissions that year. Based on historical trends, students may have an estimate of the cutoff range, but it is only after students apply to the colleges that cutoffs are determined and announced. Since the rule for determining these cutoffs is not public knowledge, students cannot perfectly predict future cutoffs. Overall, it is virtually impossible for students to precisely manipulate the side of the college cutoff they will ultimately fall on ${ }^{21}$ This in-

\footnotetext{
${ }^{20}$ According to the nationally representative India Human Development Survey of 2011-12, the average yearly income for upper caste households is approximately INR 180,000 (appropriate reference group for our analysis). This indicates that students in our sample belong to households with a relatively higher socioeconomic status, and thus not representative of the overall population.

${ }^{21}$ We also conducted the density test proposed by Cattaneo et al. (2017) and do not reject the null hypothesis that the density is smooth around the cutoff ( $p-$ value $=0.13$ ).
} 
Review of Economics and Statistics Just Accepted MS.

https://doi.org/10.1162/rest_a_00966

(C) 2020 UNU-WIDER. Published under a Creative Commons Attribution 4.0 International (CC BY 4.0) license.

ability to control the assignment variable around the cutoff also implies that pre-treatment variables would be similar around the cutoff. We next formally check for discontinuities in predetermined (pre-treatment) background characteristics such as mother's education, father's education, private high school enrollment, age, income, and religion by estimating the following reduced form regression:

$$
X_{i j}=\beta_{0}+\beta_{1} T_{i j}+\beta_{2} d_{i j}+\beta_{3} d_{i j}^{2}+\beta_{4} d_{i j} T_{i j}+\beta_{5} d_{i j}^{2} T_{i j}+\eta_{j}+\delta_{m}+v_{i j}
$$

Where $X$ is the vector of predetermined background characteristics and the right-hand side variables are as defined in equations (11) and (2) above. The results from these regressions are presented in the Online Appendix Table A4. We find that the impact of the treatment indicator, i.e., being eligible to enroll in a more selective college on the predetermined variables is mostly small and never significantly different from zero, confirming the validity of the RD design. The corresponding graphical representations are provided in Figures A2 A4 in the Online Appendix. However, as we do not have student-level panel data, we are unable to rule out discontinuities in pre-treatment outcome variables around the cutoff.

Next, we check if the probability of enrollment in a more selective college is indeed discontinuous at the cutoff. This is also proof of a strong first-stage regression, necessary for obtaining valid estimates in the second stage. In Figure 1, we plot the proportion of students enrolled in a more selective college in each 0.25 bin against the distance from the cutoff. This is done for the pooled sample and then separately for males and females. In all three sub-figures, we see a clear discontinuity in the probability of enrolling in a more selective college at the cutoff, indicating the appropriateness of the RD design. A formal estimation of the first-stage relationship between enrollment in a selective college and eligibility is provided in Table 2. We find that on average, students who are eligible to enroll in a selective college are $68 \%$ more likely to do so, indicating a strong revealed preference for more selective colleges. We 
Review of Economics and Statistics Just Accepted MS.

https://doi.org/10.1162/rest_a_00966

(C) 2020 UNU-WIDER. Published under a Creative Commons Attribution 4.0 International (CC BY 4.0) license.

find similar strong effects of the eligibility to enroll in a selective college for both males and females. As expected, compliance is not perfect, and hence, we use a fuzzy RD design and in the sections that follow, present results from the corresponding IV specification discussed in equations (1) and (2) above.

\section{Results}

\subsection{Effects on Cognition, Economic Behavior, and Personality}

Using the fuzzy RD design discussed in Section 3.1, we first examine discontinuity in average peer quality in Table 3. We find that the marginally admitted student is surrounded by peers whose average score on the high school exit exam is 2.5 percentage points higher than peers of a comparable student who just missed the cutoff (first row of Column 1). Columns 2 and 3 show that both males and females in more selective colleges are surrounded by significantly high-achieving peers. This systematic difference in average peer ability is also evident when we consider performance on another pre-treatment achievement test. Students in India also write a similar high-stakes exam at the end of grade 10. An analysis of our sample's grade 10 scores in Table 3 also points towards the higher peer quality experienced by the marginally admitted student. Figure 2 depicts the corresponding difference in peer quality. Note that in addition to the increase in average peer quality, the marginal student also has a lower ordinal rank in her peer ability distribution.

Next, in Table 4, we present the impacts of enrollment in a more selective college on cognitive attainment (in Column 1), economic preferences (in Columns 2-4), and personality traits (in Columns 5-9) for the pooled sample, males, and females in Panels A, B, and C respectively. While curriculum and exams are the same within a discipline across colleges of DU, marginal admission into a more selective college exposes students to high-achieving peers and changes their relative position in the peer ability distribution. Looking at the 
Review of Economics and Statistics Just Accepted MS.

https://doi.org/10.1162/rest_a_00966

(C) 2020 UNU-WIDER. Published under a Creative Commons Attribution 4.0 International (CC BY 4.0) license.

effects on the standardized university-level exam scores for the pooled sample in Column 1 of Panel A, we find that compared to students in less selective colleges, marginally admitted students in more selective colleges experience a 1.127 percentage point increase in their average university exam scores. Upon further examining these effects by gender, it is apparent that this overall impact is driven by the significant effects on females' test scores with no statistically significant effect for males (Column 1, Panels B and C). In particular, females in more selective colleges on average score 2.8 percentage points higher on the university exams relative to females in less selective colleges, resulting in about $4 \%$ improvement over the comparison group's mean of $69 \%$. Our finding that females make significant academic gains from exposure to more able peer environments with little or no accompanying effects on males has also been found in other studies (e.g., Angrist et al., 2009; Hastings et al., 2006; Jackson, 2010). Further, we show later in Section 4.2 that females (but not males) enrolled in more selective colleges are almost 32 percentage points more likely to have higher attendance rates than their counterparts in less selective colleges. This gender difference in attendance rates is likely to explain the observed gender gap in academic returns to more selective college and peer environments.

We also estimate the returns to enrollment in a selective college on three measures of economic preferences: competitiveness, overconfidence, and risk preference. The results are reported in Columns 2-4 of Table 4. Pooled results indicate that the marginally admitted student experiences a decline in overconfidence with no significant effects on competitiveness and risk preferences. On disaggregating the sample by gender, we observe overconfidence among marginally admitted females reduces by $0.53 \mathrm{SD}$. Our results for overconfidence show that marginal females in the more selective colleges experience a decline in overconfidence, and conversely, females below the cutoff, who are relatively high-achieving compared to their peers, become more overconfident. We hypothesize that the marginal female students in more selective colleges who are the 'small fish in a big pond' may update their beliefs about 
Review of Economics and Statistics Just Accepted MS.

https://doi.org/10.1162/rest_a_00966

(C) 2020 UNU-WIDER. Published under a Creative Commons Attribution 4.0 International (CC BY 4.0) license.

their ability as they are surrounded by peers who are academically higher-achieving than them 22

We also find that females enrolled in more selective colleges invest $0.66 \mathrm{SD}$ more in the investment game, thereby being less risk averse than their female counterparts in the less selective colleges. To the extent that females are more risk averse than males, and this gender gap in risk preferences has implications for occupational choice and other economic decision-making, this result suggests that enrollment in more selective colleges may result in a narrowing of this gender gap. Specifically, as per the expected utility theory framework, and given the nature of the investment task (Gneezy \& Potters, 1997) used to elicit risk preferences, in this task, only a risk-neutral person, or a person behaving under the Expected Value Maximization (EV) criteria should choose to invest his/her entire endowment into the risky lottery. However, a risk-averse decision-maker depending on his/her risk parameter would invest less than the full amount in the lottery. Consequently, a decrease in risk averse behavior, i.e., allocating a greater proportion of the endowment to the risky asset, can be interpreted as subjects getting closer to a risk-neutral behavior, and/or choosing according to the EV criteria in the task. Since overconfidence is positively and risk aversion is negatively related to competitiveness, a decline in risk aversion and overconfidence could plausibly explain why we do not observe any significant effects on competitiveness. Further, we find no significant effects on males' behavior.

The last set of estimates pertains to personality: Big Five traits of openness to experience, conscientiousness, extraversion, agreeableness, and emotional stability (see Columns 5-9, Table (4). In the pooled sample, we find that enrollment in a more selective college negatively affects extraversion by $0.28 \mathrm{SD}$ with no effect on other traits. Extraversion and conscientious-

\footnotetext{
${ }^{22}$ Note that this does not necessarily imply that those at the top of the distribution will also start overestimating their ability and become overconfident to the same extent. Therefore, conceptually it does not imply that there is a zero-sum game within a college for overconfidence.
} 
Review of Economics and Statistics Just Accepted MS.

https://doi.org/10.1162/rest_a_00966

(C) 2020 UNU-WIDER. Published under a Creative Commons Attribution 4.0 International (CC BY 4.0) license.

ness among marginally admitted males reduces by $0.48 \mathrm{SD}$ and $0.56 \mathrm{SD}$, respectively. Taken together, these estimates for male students suggest a diminished self-concept stemming from their lower academic position within their college rank, resulting in negative effects on economically valuable personality traits, capturing 'small fish in a big pond' effects. Murphy and Weinhardt (2020) also find males to be influenced more significantly on account of rank concerns. We find similar results using alternative measures. In results reported in Table A5 in the Online Appendix, membership in college-level societies, another measure of extrovert behavior, is also lower among males enrolled in more selective colleges. Similarly, we also find that males at the margin of admission in more selective colleges report lower grit, which is highly correlated with conscientiousness. We also observe a decline in openness to experience and agreeableness for males, though neither is statistically significant. In light of findings that show that conscientiousness and extraversion matter for academic performance (Lundberg, 2013), the adverse effects on these personality traits for the marginally admitted males might explain why we observe no gains in exam scores for them 23 Lastly, it is also possible that exposure to being in a selective college may affect some socioemotional skills with a lag and become prominent only in the long run, such that our effects are underestimated.

It is possible that impacts on measured outcomes differ by length of exposure. To examine this, we allow for the effects of college quality to vary by student cohorts (second and third year), and find that the main results in Table 4 do not vary by cohort. These results are reported in Table A6 in the Online Appendix.

\footnotetext{
${ }^{23}$ Due to a modest sample size, some of our coefficients are imprecisely estimated and we are unable to reject the null of equality in coefficients between males and females. Gender differences are significant for outcomes related to risk preferences $(p-$ value $=0.002)$ and conscientiousness $(p-$ value $=0.012)$, but not for university exam scores $(p$-value $=0.131)$, overconfidence $(p-$ value $=0.365)$, and extraversion $(p-$ value $=0.571)$.
} 
Review of Economics and Statistics Just Accepted MS.

https://doi.org/10.1162/rest_a_00966

(C) 2020 UNU-WIDER. Published under a Creative Commons Attribution 4.0 International (CC BY 4.0) license.

\subsection{Pathways}

Owing to the design of the admissions process in colleges at DU, we have so far shown and argued that differences in peer quality and relative rank in the peer distribution are driving our main results. In this section, we explore a variety of other potential channels that could explain our main findings.

In Column 1 in Table 5, we examine differences in attendance rates ${ }^{24}$ We construct a binary variable for high attendance that takes a value 1 if subjects report having class attendance rates of $75 \%$ and higher, and 0 if attendance is below $75 \%$. We find that while there is no significant difference for males in the probability of high attendance, females enrolled in selective colleges have a greater probability of high attendance than females in less selective colleges. This indicates that they are present in class more often and therefore have an opportunity to learn from and engage with their peers, making it one of the competing explanations for gains on cognitive and behavioral outcomes. This finding fits in with the general observed pattern of females having better study habits (Angrist et al., 2009; Hastings et al., 2006).

Next, we examine attendance of subjects relative to their classmates. In Column 2, we construct an outcome variable that takes the value 1 if the subject attended classes less often than their classmates. We find that marginally admitted males are more likely to skip classes than their classmates in less selective colleges. This points towards weakened selfconcept among males on account of their lower academic position in the college, potentially indicating higher mental or psychic costs of investing effort. Elsner and Isphording (2017) also find a similar effect in that students with lower ordinal rank are more likely to be absent from classes.

\footnotetext{
${ }^{24}$ Since attendance is self-reported, presence of random measurement error in this outcome variable is likely to bias the standard errors upwards.
} 
Review of Economics and Statistics Just Accepted MS.

https://doi.org/10.1162/rest_a_00966

(C) 2020 UNU-WIDER. Published under a Creative Commons Attribution 4.0 International (CC BY 4.0) license.

Subjects could also experience learning gains due to complementary investments in education in the form of external private tutorials and remedial classes. These can improve test scores independent of the college and peer environment. However, as shown in Column 3 of Table 6 , we do not find any discontinuity in the probability of using external tutorials for either males or females.

Differences in indicators of teacher quality and presence could also matter for students' academic and non-academic outcomes (e.g., Hoffmann \& Oreopoulos, 2009; Jackson, 2018). As a measure of teacher presence, we asked students if teachers frequently cancelled classes. Results in Column 4 show no discontinuity in the probability of classes being cancelled. Finally, results in Column 5 indicate that student-teacher ratio, an additional measure of teaching quality, also does not vary around the cutoff.

Finally, there might be unobserved differences across colleges in student-teacher interactions (such as informal in-class tests and levels of teacher attention and feedback) that may affect students' perception about their ability and rank. It is difficult to get information on these nuanced student-teacher interactions. Even if we assume these to be more prevalent in more selective colleges, it is not clear if the feedback re-affirms or mitigates students' concerns about relative rank. Thus, the net effect of such unobserved student-teacher interactions is ambiguous.

\subsection{Robustness}

In this section, we discuss a number of robustness checks. A crucial concern relates to sample selection bias such that applicants who narrowly fail to get admitted into selective colleges in DU may withdraw from DU to seek admission in other non-DU colleges/universities instead of taking admission in a less selective DU college. Thus, those who remain and choose a lower-ranking college in DU may be systematically different in terms of their behaviour and 
Review of Economics and Statistics Just Accepted MS.

https://doi.org/10.1162/rest_a_00966

(C) 2020 UNU-WIDER. Published under a Creative Commons Attribution 4.0 International (CC BY 4.0) license.

socioemotional skills from those who exit from DU, inducing selection into the comparison group. In the absence of data on applications, that could have plausibly allowed us to identify such attrition during the admissions process (i.e., discouraged applicants at the margin), we surveyed 298 grade 12 students across 11 schools in New Delhi in 2019, who were on the verge of entry into higher education, and collected information on their intentions for higher education such as colleges/universities they are interested in applying to and attending, the Big Five traits and background characteristics. We use this survey to conduct bounding exercises.

We find DU to be the top choice for an overwhelming share $(93.3 \%)$ of the high school sample. Among these students who intend to apply to DU (our pool of potential applicants to DU), only $4 \%$ are potential attritors, i.e., they state that if they do not get admission into the top rank colleges, they will also decline admissions to lower-ranking DU colleges, and seek admission elsewhere. Importantly, we find that the decisions to not apply to DU and to exit DU in the event of not getting into one's preferred college are not correlated with any of the Big Five personality traits (see Table A7 in the Online Appendix).

Nevertheless, we construct bounds for our treatment effects by modifying the procedure of Lee (2009) in the RD context. To construct the lower (upper) bounds on the treatment we trim the top (bottom) $4 \%$ of the dependent variable in the treatment colleges and re-run our main regressions. These results are reported in Online Appendix Tables A8 and A9 for males and females respectively. Our estimated treatment effects calibrated using the $4 \%$ attrition rate in the school survey are similar to the main results reported in Table $44^{25}$

\footnotetext{
${ }^{25}$ We thank the editor for this suggestion. We also conduct bounding exercises assuming 7, 10, and $15 \%$ attrition to examine the sensitivity of our estimates. As shown in Online Appendix Tables A8 and A9, the lower bounds are statistically significant for all male and female outcomes at 7,10 , and $15 \%$ attrition rate (except for exam score for females). While we present both upper and lower bound estimates, the lower bounds may be more relevant for us if the "marginally disappointed" individuals (with higher cognitive ability, extraversion, conscientiousness, overconfidence, and risk) were more likely to seek out non-DU alternatives
} 
Review of Economics and Statistics Just Accepted MS.

https://doi.org/10.1162/rest_a_00966

(C) 2020 UNU-WIDER. Published under a Creative Commons Attribution 4.0 International (CC BY 4.0) license.

The second concern relates to the possibility of Type I error that increases with the number of outcomes tested. We use the method in Anderson (2008) to correct the standard errors for multiple hypotheses testing, by families of outcomes. Our results are largely robust to this correction, and the sharpened q-values are reported in square brackets in Table 1 .

Third, the presence of differential participation in our study around the cutoff would bias our estimates. Using administrative data on class sizes obtained under the Right to Information Act, we calculate the share of students who participated in our study. The average participation rate is $58 \%$ in our sample. We find no evidence of differential participation around the cutoff, thereby alleviating participation-related selection concerns (Table A10 in the Online Appendix).

Fourth, students who move across colleges during the admissions process could be systematically different from those who could have potentially moved, but did not, i.e., those with high school exit exam scores exceeding the required cutoff, but currently enrolled in a comparison college, raising selection related concerns. We find no difference between movers and potential movers in terms of the predetermined characteristics, with movers being negligibly older (Table A11 in the Online Appendix), attenuating the aforementioned concerns.

Fifth, while we have some differences in sample sizes across regressions in Table 4 due to non-response (in the range of $0.1-2 \%$ across all outcomes), our results are robust to limiting the sample to those respondents for whom we have data on all the outcomes (see Table A12 in the Online Appendix) ${ }^{26}$

Sixth, we show that the LATE estimates reported earlier in Table 4 are robust to: (i) excluding the predetermined controls; (ii) using triangular weights that assign greater weights to observations closer to the cutoff instead of rectangular weights; and (iii) using outcomefor college admission creating sample selection in the comparison group.

${ }^{26} \mathrm{We}$ also find the probability of missing data on the outcomes is not systematic around the cutoff except for males' overconfidence (Table A13 in the Online Appendix). 
Review of Economics and Statistics Just Accepted MS.

https://doi.org/10.1162/rest_a_00966

(C) 2020 UNU-WIDER. Published under a Creative Commons Attribution 4.0 International (CC BY 4.0) license.

specific optimal bandwidths as prescribed by Calonico et al. (2014) (see Tables A14 and A15 in the Online Appendix).

Next, another concern could be that the pools of applicants might have been different across treatment and comparison colleges during the admissions process. In the survey, we also collected data on the colleges students had applied to. We provided students with a list of 17 colleges (of which 15 were our sample colleges), and asked them to indicate all colleges they had applied to. While this may be subject to recall bias since at least 2 years had elapsed since admission, we use this data in the following manner. We construct a variable applicant that takes a value 1 for all students currently enrolled in treatment colleges as well as for any student from the comparison college who also applied to the treatment college, 0 otherwise. We find that $87.6 \%$ of individuals enrolled in the comparison colleges had also applied to the treatment colleges. Our main results in Table 5 are robust to limiting the sample to these "applicants" (Table A16 in the Online Appendix).

Finally, in estimating the returns to college quality, we also implicitly assume that students prefer being in a more selective college to a less selective one. We now show that our results are largely robust to relaxing this assumption. In the survey, we asked students to rank a subset of the sample colleges as they would have at the time of admission. We use this data in the following way. While constructing each of our RD samples, we limit our sample to students who strictly rank all the treated colleges higher than the comparison colleges and do not rank any of the comparison colleges at least as high as any of the treated colleges. While the sample now is limited and there is bound to be some recall error, we find that the effects on most economic preferences and personality traits continue to hold (Table A17 in the Online Appendix). 
Review of Economics and Statistics Just Accepted MS.

https://doi.org/10.1162/rest_a_00966

(C) 2020 UNU-WIDER. Published under a Creative Commons Attribution 4.0 International (CC BY 4.0) license.

\subsection{Heterogeneity}

The existing literature has mainly studied effects of enrollment in top educational institutions (e.g., Abdulkadiroğlu et al., 2014; Hoekstra, 2009) or average effects of enrolling in relatively more selective institutions using data from a range of institutions (e.g., Jackson, 2010; Lucas \& Mbiti, 2014: Pop-Eleches \& Urquiola, 2013). However, returns to educational quality may be non-linear and vary across the quality distribution. For example, Hoekstra et al. (2018) examine schools of varying selectivity in China and find effects stemming from enrollment present in only the most elite schools.

In a similar vein, in Table 6 we examine if behavioral responses to college and peer environments differ depending on how selective the college is. For this purpose, we re-estimate our regressions separately examining (i) the effect of enrolling in a rank 1 (most selective) colleges in Panels A and B, and (ii) the effects of enrolling in ranks 2 and 3 (less selective) colleges, that is, excluding rank 1 college cutoffs in Panels $\mathrm{C}$ and D. The returns to college quality may vary across these two samples as the scope for improvement based on peer learning may be lower in rank 1 colleges. Further, the adverse effects of lower relative rank on academic self-concept may be more acutely felt in the more selective colleges.

We find that enrolling in a rank 1 college reduces conscientiousness, openness to experience, and overconfidence among marginally admitted males, and increases risk taking and reduces overconfidence for females. In contrast, we find that excluding rank 1 college cutoffs only reduces extraversion for males and increases risk taking among females. Overall, the results suggest that males are more likely to be susceptible to relative rank concerns in the most selective colleges which results in negative effects on personality and behavior reported in Panel A compared to Panel C, Table 6. On the other hand, for females, the results in Panels $\mathrm{B}$ and D remain largely similar. However, these results should be interpreted with some caution as we lack the statistical power to conduct a finer analysis. 
Review of Economics and Statistics Just Accepted MS.

https://doi.org/10.1162/rest_a_00966

(C) 2020 UNU-WIDER. Published under a Creative Commons Attribution 4.0 International (CC BY 4.0) license.

\section{Conclusion}

The existing empirical work on the returns to college quality has largely focused on test scores as outcomes of human capital, and generated mixed evidence. Scant attention has been paid to underlying economic preferences and socioemotional traits - facets of human capital that recent research has documented as being important for one's economic progress.

In this paper, our aim has been to fill this critical gap by examining the effects of college selectivity on cognitive, behavioral, and socioemotional outcomes, using data collected from a large sample of students at a leading Indian university. Exploiting the variation in college admission cutoffs, we compare students just above the cutoff with those just below the cutoff to determine the causal impact of enrollment in a selective college, where they are surrounded by relatively high-achieving peers and have a lower relative rank in their peer group. We find that marginally admitted female students in more selective colleges experience improvements in scores on standardized university exams. In terms of behavior and personality, we find that females just above the cutoff become less risk averse and less overconfident. On the other hand, males in these colleges experience declines in extraversion and conscientiousness pointing towards a weakened self-concept due to a lower relative rank in their peer group, capturing 'small fish in a big pond' effect. Further, we are also able to show that variations in college qualities stem mainly from variations in peer qualities (and rank) with no differences in teacher presence or student-teacher ratios around the cutoff.

Some caveats remain. First, while our study shows that the effects of selective colleges are not unequivocally positive for the outcomes we consider in the short-run, it is important to bear in mind that in the long-run, elite colleges are still likely to lead to higher wages, access to well-connected alumni networks, and better marriage prospects. Second, it is possible that exposure to being in a selective college may impact some socioemotional skills only in the long run, such that our effects are underestimated. Third, while our study does not encompass 
Review of Economics and Statistics Just Accepted MS.

https://doi.org/10.1162/rest_a_00966

(C) 2020 UNU-WIDER. Published under a Creative Commons Attribution 4.0 International (CC BY 4.0) license.

the entire population of DU students, to the extent the admissions process is similar to that for economics and commerce, our overall framework on peer quality and rank concerns should matter in a similar way for other disciplines as well. However, it should be noted that as DU is one of the premier universities in India, its students are not representative of the average Indian college student. Although this study is unable to comment on the long-run effects on personality traits and labor market outcomes, it should encourage follow-up work that can can shed light on longer-term impacts of such peer effects. 
Review of Economics and Statistics Just Accepted MS.

https://doi.org/10.1162/rest_a_00966

(C) 2020 UNU-WIDER. Published under a Creative Commons Attribution 4.0 International (CC BY 4.0) license.

\section{References}

Abdulkadiroğlu, A., Angrist, J.D., and Pathak, P.A. (2014). The elite illusion: Achievement effects at Boston and New York exam schools. Econometrica, 82(1), 137-196.

Acevedo, P., Cruces, G., Gertler, P., and Martinez, S. (2017). Living up to expectations: How job training made women better off and men worse off. NBER Working Paper No. 23264.

Adhvaryu, A., Kala, N., and Nyshadham, A. (2018). The skills to pay the bills: Returns to on-the-job soft skills training. NBER Working Paper No. 24313.

Ajayi, K.F. (2014). Does school quality improve student performance? New evidence from Ghana. Working Paper.

Almlund, M., Duckworth, A.L., Heckman, J.J. and Kautz, T. (2011). Personality psychology and economics, in E.A. Hanushek, S. Machin and L. Woessmann, (eds.), Handbook of the Economics of Education, vol. 4, 1-181, Amsterdam: North-Holland.

Anderson, M.L. (2008). Multiple inference and gender differences in the effects of early intervention: A re-evaluation of the Abecedarian, Perry Preschool, and early training projects. Journal of the American Statistical Association, 103(484), 1481-1495.

Angrist, J., Lang, D., and Oreopoulos, P. (2009). Incentives and services for college achievement: Evidence from a randomized trial. American Economic Journal: Applied Economics, 1(1), 136-63.

Bartling, B., Fehr, E., Marechal, M.A., and Schunk, D. (2009). Egalitarianism and competitiveness. American Economic Review: Papers 86 Proceedings, 99(2), 93-98.

Booij, A.S., Leuven, E., and Oosterbeek, H. (2017). Ability peer effects in university: Evidence from a randomized experiment. Review of Economic Studies, 84, 547-578. 
Review of Economics and Statistics Just Accepted MS.

https://doi.org/10.1162/rest_a_00966

(C) 2020 UNU-WIDER. Published under a Creative Commons Attribution 4.0 International (CC BY 4.0) license.

Borghans, L., Duckworth, A.L., Heckman, J.J., and ter Weel, B. (2008). The economics and psychology of personality traits. Journal of Human Resources, 43(4), 972-1059.

Borker, G. (2017). Safety first: Perceived risk of street harassment and educational choices of women. Working paper.

Buser, T., Niederle, M., and Oosterbeek, H. (2014). Gender, competitiveness and career choices. Quarterly Journal of Economics, 129(3), 1409-1447.

Calonico, S., Cattaneo, M. D., and Titiunik, R. (2014). Robust nonparametric confidence intervals for regression discontinuity designs. Econometrica, 82(6), 2295-2326.

Cameron, A.C, Gelbach, J.G., and Miller, D.L. (2011). Robust Inference with Multi-Way Clustering. Journal Business and Economic Statistics, 29(2), 238-249.

Campos, F., Frese, M., Goldstein, M., Iacovone, L., Johnson, H. C., McKenzie, D., and Mensmann, M. (2017). Teaching personal initiative beats traditional training in boosting small business in West Africa. Science, 357(6357),1287-1290.

Carrell, S.E., Sacerdote, B.I., and West, J.E. (2013). From natural variation to optimal policy? The importance of endogenous peer group formation. Econometrica, 81(3), 855882.

Cattaneo, M. D., Jansson, M., and Ma, X. (2019). Simple Local Polynomial Density Estimators. Journal of the American Statistical Association, forthcoming

Chandrasekhar, S., and Sharma, A. (2014). Internal migration for education and employment among youth in India. Indira Gandhi Institute of Development Research WP-2014-004.

Charness, G., and Viceisza, A. (2016). Three risk elicitation methods in the field: evidence from rural Senegal. Review of Behavioral Economics, 3(2), 145-171.

Chuang, Y., and Schechter, L. (2015). Stability of experimental and survey measures of 
Review of Economics and Statistics Just Accepted MS.

https://doi.org/10.1162/rest_a_00966

(C) 2020 UNU-WIDER. Published under a Creative Commons Attribution 4.0 International (CC BY 4.0) license.

risk, time, and social preferences: A review and some new results. Journal of Development Economics, 117, 151-170.

Cicala, S., Fryer, R. G., and Spenkuch, J. L. (2018). Self-selection and comparative advantage in social interactions. Journal of the European Economic Association, 16(4), 9831020.

Dasgupta, U., Gangadharan, L., Maitra, P., Mani, S., and Subramanian, S. (2015). Choosing to be trained: Do behavioral traits matter? Journal of Economic Behavior 83 Organization, $110,145-159$.

Dasgupta, U., Gangadharan, L., Maitra, P., and Mani, S. (2017). Searching for Preference Stability in a State Dependent World. Journal of Economic Psychology, 62, 17-32.

Dean, E.B., Schilbach, F., and Schofield, H. (2019). Poverty and cognitive function. In C.B. Barrett, M.R. Carter, and J-P. Chavas (Eds.) The Economics of Poverty Traps, 57-118.

Elsner, B., and Isphording, I. (2017). A big fish in a small pond: Ability rank and human capital investment. Journal of Labor Economics, 35(3), 787-828.

Elsner, B., and Isphording, I. (2018). Rank, sex, drugs, and crime. Journal of Human Resources, 53(2), 356-381.

Fabregas, R. (2017). A better school but a worse position: The effects of marginal school admissions in Mexico City. Working Paper.

Feld, J., and Zölitz, U. (2017). Understanding peer effects: On the nature, estimation, and channels of peer effects. Journal of Labor Economics, 35(2), 387-428.

Gneezy, U. and Potters, J. (1997). An experiment on risk taking and evaluation periods. Quarterly Journal of Economics, 112(2), 631-645.

Gosling, S.D., Rentfrow, P.J., and Swann Jr., W.B. (2003). A very brief measure of the 
Review of Economics and Statistics Just Accepted MS.

https://doi.org/10.1162/rest_a_00966

(C) 2020 UNU-WIDER. Published under a Creative Commons Attribution 4.0 International (CC BY 4.0) license.

Big-Five personality domains. Journal of Research in Personality, 37, 504-528.

Hanushek, E.A., and Woessmann, L. (2008). The role of cognitive skills in economic development. Journal of Economic Literature, 46(3), 607-668.

Hastings, J.S., Kane, T., and Staiger, D. (2006). Gender, performance and preferences: do girls and boys respond differently to school environment? Evidence from school assignment by randomized lottery. American Economic Review: Papers $\&$ Proceedings, 96(2), 232236.

Hoekstra, M. (2009). The effect of attending the flagship state university on earnings: a discontinuity-based approach. Review of Economics and Statistics, 91(4), 717-724.

Hoekstra, M., Mouganie, P., and Wang, Y. (2018). Peer quality and the academic benefits to attending better schools. Journal of Labor Economics, 36(4), 841-884.

Hoffmann, F., and Oreopoulos, P. (2009). Professor qualities and student achievement. Review of Economics and Statistics, 91(1), 83-92.

Jain, T., and Kapoor, M. (2015). The impact of study groups and roommates on academic performance. Review of Economics and Statistics, 97(1), 44-54.

Jackson, C. K. (2010). Do students benefit from attending better schools? Evidence from rule-based student assignments in Trinidad and Tobago. Economic Journal, 120(549), 13991429.

Jackson, C. K. (2018). What Do Test Scores Miss? The Importance of Teacher Effects on NonĐTest Score Outcomes. Journal of Political Economy, 126(5), 2072-2107.

Jaeger, D.A., Dohmen, T., Falk, A., Huffman, D., Sunde, U., and Bonin, H. (2010). Direct Evidence on Risk Attitudes and Migration. The Review of Economics and Statistics, 92(3), 684-689. 
Review of Economics and Statistics Just Accepted MS.

https://doi.org/10.1162/rest_a_00966

(C) 2020 UNU-WIDER. Published under a Creative Commons Attribution 4.0 International (CC BY 4.0) license.

Kamas, L., and Preston, A. (2012). The importance of being confident; gender, career choice, and willingness to compete. Journal of Economic Behavior \& Organization, 83, 82-97.

Karni, E., and Safra, Z. (1995). The Impossibility of Experimental Elicitation of Subjective Probabilities. Theory and Decision, 38 (3), 313-320.

Kling, J.R., Ludwig, J., and Katz, L.F. (2005). Neighborhood effects on crime for female and male youth: evidence from a randomized housing mobility experiment. Quarterly Journal of Economics, 120(1), 87-130.

Koellinger, P., Minniti, M., and Schade, C. (2007). 'I think I can, I think I can': Overconfidence and entrepreneurial behavior. Journal of Economic Psychology, 28, 502 - 527.

Lee, D.S. (2009). Training, wages, and sample selection: Estimating sharp bounds on treatment effects. The Review of Economic Studies, 76(3), 1071-1102.

Lee, D.S., and Card, D. (2008). Regression discontinuity inference with specification error. Journal of Econometrics, 142, 655-674.

Lee, D. S., and Lemieux, T. (2010). Regression discontinuity designs in economics. Journal of Economic Literature, 48(2), 281-355.

Lucas, A.M., and Mbiti, I.M. (2014). Effects of school quality on student achievement: Discontinuity evidence from Kenya. American Economic Journal: Applied Economics, 6(3), 234-263.

Lundberg, S. (2013). The college type: Personality and educational inequality. Journal of Labor Economics, 31(3), 421-441.

Lyle, D.S. (2009). The effects of peer group heterogeneity on the production of human capital at West Point. American Economic Journal: Applied Economics, 1(4), 69-84.

Marsh, H., Seaton, M., Trautwein, U., Ludtke, O., Hau, O'Mara, A., and Craven, R. (2008). 
Review of Economics and Statistics Just Accepted MS.

https://doi.org/10.1162/rest_a_00966

(C) 2020 UNU-WIDER. Published under a Creative Commons Attribution 4.0 International (CC BY 4.0) license.

The big fish little pond effect stands up to critical scrutiny: Implications for theory, methodology, and future research. Educational Psychology Review, 20(3), 319-350.

Moore, D.A., and Healy, P.J. (2008). The Trouble with Overconfidence. Psychological Review, 115(2), 502-517.

Murphy, R., and Weinhardt, F. (2020). Top of the class: The importance of ordinal rank. Review of Economic Studies, forthcoming.

Niederle, M. (2016). Gender. In J.H. Kagel and A.E. Roth (Eds.) Handbook of Experimental Economics, Vol. 2, 481-553.

Niederle, M. and Vesterlund, L. (2007). Do women shy away from competition? Do men compete too much? Quarterly Journal of Economics, 122(3), 1067-1101.

Nordman, C.J., Sarr, L.R., and Sharma, S. (2019). Skills, personality traits and gender wage gaps: Evidence from Bangladesh. Oxford Economic Papers, 71(3), 687-708.

Oreopoulos, P., and Salvanes, K.G. (2011). Priceless: The nonpecuniary benefits of schooling. Journal of Economic Perspectives, 25(1), 159-184.

Pop-Eleches, C., and Urquiola, M. (2013). Going to a better school: Effects and behavioral responses. American Economic Review, 103(4), 1289-1324.

Saavedra, J. (2009). The learning and early labor market effects of college quality: a regression discontinuity analysis. Working paper.

Sacerdote, B. (2011). Peer effects in education: How might they work, how big are they and how much do we know thus far? Handbook of the Economics of Education, Vol. 3, 249-277.

Schmitt, D. P., Realo, A., Voracek, M., and Allik, J. (2008). Why can't a man be more like a woman? Sex differences in Big Five personality traits across 55 cultures. Journal of 
Review of Economics and Statistics Just Accepted MS.

https://doi.org/10.1162/rest_a_00966

(C) 2020 UNU-WIDER. Published under a Creative Commons Attribution 4.0 International (CC BY 4.0) license.

Personality and Social Psychology, 94, 168-182.

Schurer, S., Kassenboehmer, S.C., and Leung, F. (2018). University education and noncognitive skill development. Oxford Economic Papers, 70(2), 538-562.

Sekhri, S. (2020). Prestige matters: Wage premium and value addition in elite colleges. American Economic Journal: Applied Economics, 12(3), 207-225.

Sharma, S., and Tarp, F. (2018). Does managerial personality matter? Evidence from firms in Vietnam. Journal of Economic Behavior \& Organization, 150-432-445.

Sönmez, T. and Ünver, U. (2011). Matching, allocation, and exchange of discrete resources, in J. Benhabib, A. Bisin, and M. Jackson (eds.), Handbook of Social Economics, Handbook of Social Economics, Vol. 1A, 781-852, The Netherlands: North-Holland.

Specht, J., Egloff, B., and Schmukle, S.C. (2011). Stability and change of personality across the life course: the impact of age and major life events on mean-level and rank-order stability of the Big Five. Journal of Personality and Social Psychology, 101(4), 862-882. 
Review of Economics and Statistics Just Accepted MS.

https://doi.org/10.1162/rest_a_00966

(C) 2020 UNU-WIDER. Published under a Creative Commons Attribution 4.0 International (CC BY 4.0) license.

\section{Figures and Tables}

(a) Full Sample

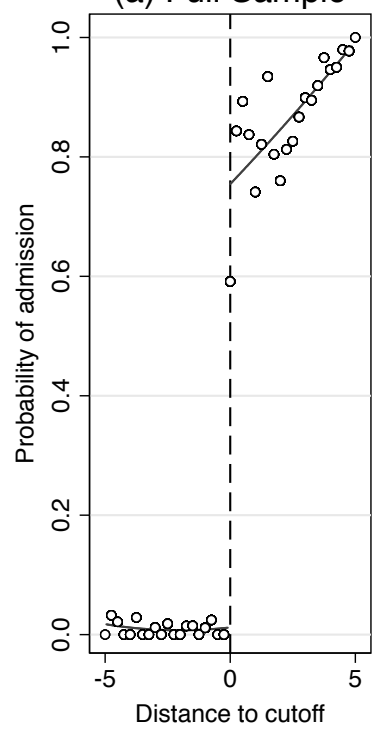

(b) Males

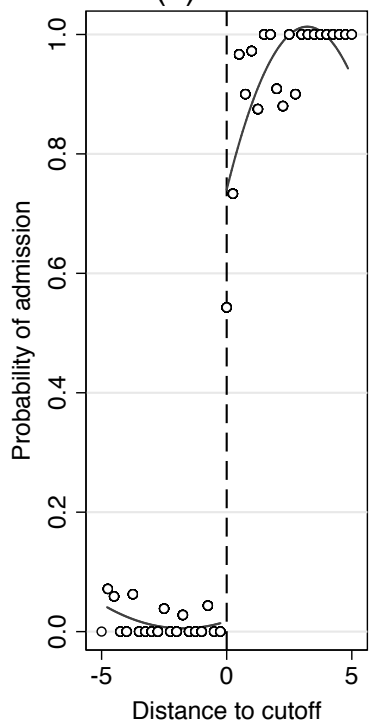

(c) Females

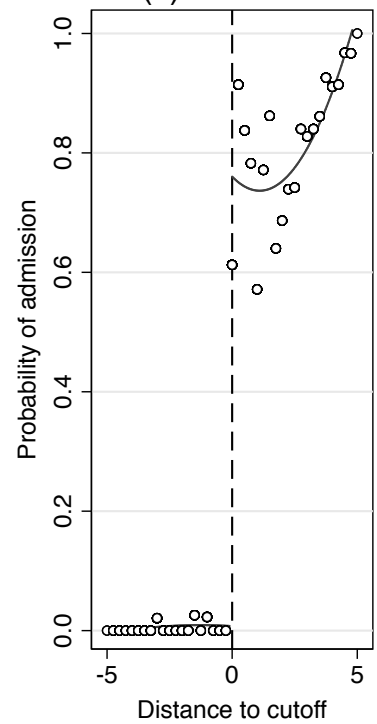

\section{Quadratic fit $\circ 0.25$ bins}

Figure 1: First-stage Relationship 
Review of Economics and Statistics Just Accepted MS.

https://doi.org/10.1162/rest_a_00966

(C) 2020 UNU-WIDER. Published under a Creative Commons Attribution 4.0 International (CC BY 4.0) license.

(a) Average grade 12 score

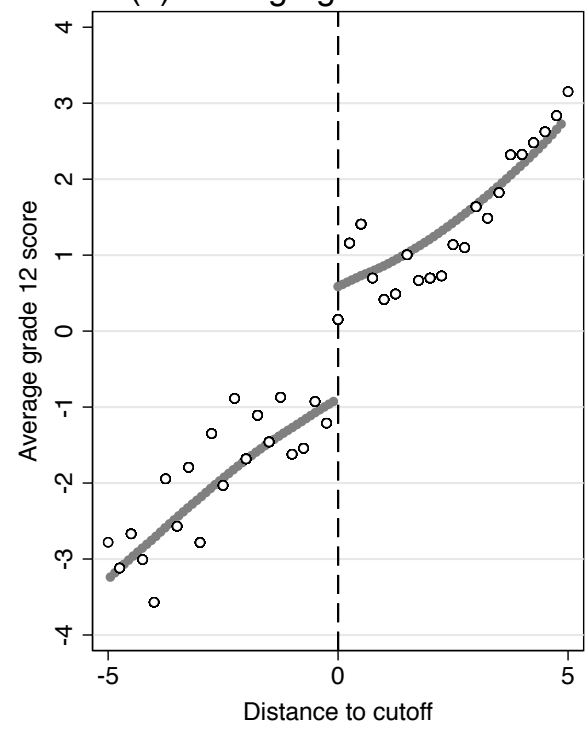

(b) Average grade 10 score

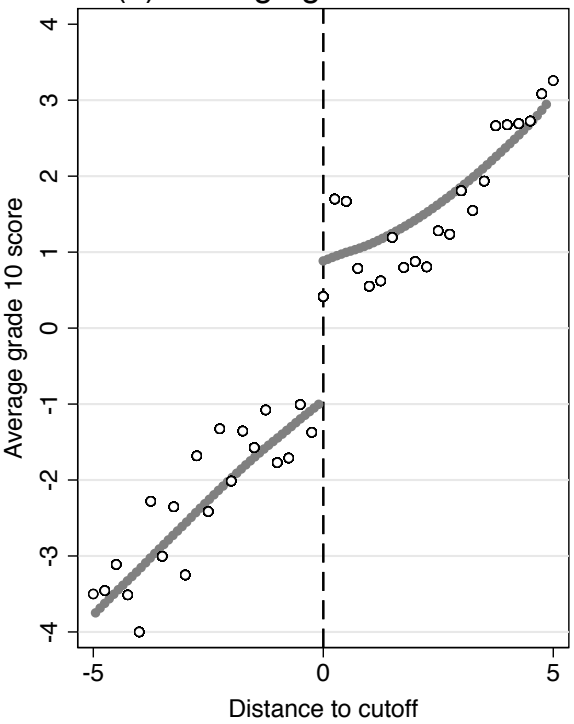

- Kernel weighted local polynomial fit $\quad \circ 0.25$ bins

Notes: This figure plots residual terms obtained by regressing average peer quality on cutoff fixed effects against distance from the threshold.

Figure 2: College Quality and Peers 
Review of Economics and Statistics Just Accepted MS.

https://doi.org/10.1162/rest_a_00966

(C) 2020 UNU-WIDER. Published under a Creative Commons Attribution 4.0 International (CC BY 4.0) license.

Table 1: Summary Statistics

\begin{tabular}{|c|c|c|c|c|}
\hline & $\begin{array}{c}\text { Full Sample } \\
\text { (1) }\end{array}$ & $\begin{array}{l}\text { Males } \\
(2)\end{array}$ & $\begin{array}{c}\text { Females } \\
(3)\end{array}$ & $\begin{array}{c}\text { Difference } \\
(4)\end{array}$ \\
\hline \multicolumn{5}{|c|}{ Panel A: Cognitive attainment } \\
\hline University exam score & $\begin{array}{l}70.44 \\
(7.39)\end{array}$ & $\begin{array}{l}70.19 \\
(7.43)\end{array}$ & $\begin{array}{l}70.64 \\
(7.36)\end{array}$ & -0.45 \\
\hline \multicolumn{5}{|c|}{ Panel B: Economic preferences } \\
\hline Competitiveness & $\begin{array}{c}0.31 \\
(0.46)\end{array}$ & $\begin{array}{c}0.41 \\
(0.49)\end{array}$ & $\begin{array}{c}0.24 \\
(0.43)\end{array}$ & $0.17^{* * *}$ \\
\hline Overconfidence & $\begin{array}{c}1.64 \\
(1.22)\end{array}$ & $\begin{array}{c}1.66 \\
(1.20)\end{array}$ & $\begin{array}{c}1.63 \\
(1.24)\end{array}$ & 0.03 \\
\hline Risk preference & $\begin{array}{c}46.59 \\
(19.08)\end{array}$ & $\begin{array}{l}49.88 \\
(21.71)\end{array}$ & $\begin{array}{c}43.99 \\
(16.24)\end{array}$ & $5.89^{* * *}$ \\
\hline \multicolumn{5}{|l|}{ Panel C: Personality traits } \\
\hline Extraversion score & $\begin{array}{c}4.77 \\
(1.43)\end{array}$ & $\begin{array}{c}4.69 \\
(1.43)\end{array}$ & $\begin{array}{c}4.83 \\
(1.42)\end{array}$ & $-0.14^{* *}$ \\
\hline Agreeableness score & $\begin{array}{c}5.20 \\
(1.16)\end{array}$ & $\begin{array}{c}4.97 \\
(1.16)\end{array}$ & $\begin{array}{c}5.38 \\
(1.12)\end{array}$ & $-0.41^{* * *}$ \\
\hline Conscientiousness score & $\begin{array}{c}5.31 \\
(1.26)\end{array}$ & $\begin{array}{c}5.20 \\
(1.29)\end{array}$ & $\begin{array}{c}5.40 \\
(1.23)\end{array}$ & $-0.20 * * *$ \\
\hline Emotional stability score & $\begin{array}{c}4.54 \\
(1.38)\end{array}$ & $\begin{array}{c}4.65 \\
(1.40)\end{array}$ & $\begin{array}{c}4.45 \\
(1.36)\end{array}$ & $0.20 * * *$ \\
\hline Openness to experience score & $\begin{array}{c}5.42 \\
(1.12)\end{array}$ & $\begin{array}{c}5.44 \\
(1.10)\end{array}$ & $\begin{array}{c}5.41 \\
(1.14)\end{array}$ & 0.03 \\
\hline \multicolumn{5}{|c|}{ Panel D: Background characteristics } \\
\hline Age & $\begin{array}{l}19.66 \\
(0.86)\end{array}$ & $\begin{array}{l}19.69 \\
(0.86)\end{array}$ & $\begin{array}{l}19.65 \\
(0.86)\end{array}$ & 0.04 \\
\hline Religion & $\begin{array}{c}0.92 \\
(0.27)\end{array}$ & $\begin{array}{c}0.92 \\
(0.28)\end{array}$ & $\begin{array}{c}0.93 \\
(0.26)\end{array}$ & -0.01 \\
\hline Private School & $\begin{array}{c}0.85 \\
(0.36)\end{array}$ & $\begin{array}{c}0.85 \\
(0.36)\end{array}$ & $\begin{array}{c}0.84 \\
(0.36)\end{array}$ & 0.01 \\
\hline Income & $\begin{array}{c}0.30 \\
(0.46)\end{array}$ & $\begin{array}{c}0.30 \\
(0.46)\end{array}$ & $\begin{array}{c}0.31 \\
(0.46)\end{array}$ & -0.01 \\
\hline Mother's Education & $\begin{array}{c}0.75 \\
(0.43)\end{array}$ & $\begin{array}{c}0.73 \\
(0.44)\end{array}$ & $\begin{array}{c}0.77 \\
(0.42)\end{array}$ & $-0.04^{* *}$ \\
\hline Father's Education & $\begin{array}{c}0.78 \\
(0.41)\end{array}$ & $\begin{array}{c}0.78 \\
(0.41)\end{array}$ & $\begin{array}{c}0.79 \\
(0.41)\end{array}$ & -0.00 \\
\hline
\end{tabular}

Notes: Religion is an indicator variable for being a Hindu; income is an indicator variable for monthly family income being below Rs. 50,000; mother's and father's education are indicator variables for tertiary education; private school is an indicator variable for graduation from a private high school. Personality traits' scores range from 0-7. For second and third year students, we have the average exam scores based on 3 semesters and 5 semesters respectively. Sample restricted to $+/-5$ window around the cutoff. $*$ significant at $10 \%,{ }^{* *}$ significant at $5 \%,{ }^{* * *}$ significant at $1 \%$. 
Review of Economics and Statistics Just Accepted MS.

https://doi.org/10.1162/rest_a_00966

(C) 2020 UNU-WIDER. Published under a Creative Commons Attribution 4.0 International (CC BY 4.0) license.

Table 2: First-stage Discontinuity

\begin{tabular}{lccc}
\hline & $\begin{array}{c}\text { Full Sample } \\
(1)\end{array}$ & $\begin{array}{c}\text { Males } \\
(2)\end{array}$ & $\begin{array}{c}\text { Females } \\
(3)\end{array}$ \\
\hline Without controls & $\begin{array}{c}0.680^{* * *} \\
(0.066)\end{array}$ & $\begin{array}{c}0.698^{* * *} \\
(0.086)\end{array}$ & $\begin{array}{c}0.626^{* * *} \\
(0.078)\end{array}$ \\
Observations & 2393 & 1059 & 1334 \\
& & & \\
With controls & $0.681^{* * *}$ & $0.702^{* * *}$ & $0.629^{* * *}$ \\
& $(0.063)$ & $(0.082)$ & $(0.074)$ \\
Observations & 2368 & 1043 & 1325 \\
\hline
\end{tabular}

Notes: This table shows the first-stage discontinuity results using a flexible second order polynomial described in the text. We control for mother's education, father's education, private school enrollment, age, income, and religion in all specifications (see notes in Table 1 for variable definitions). All regressions also include cutoff and month of survey fixed effects. Standard errors clustered at 0.25 bins of the centered high school exit exam score level are reported in parentheses. ${ }^{*}$ significant at $10 \%,{ }^{* *}$ significant at $5 \%,{ }^{* * *}$ significant at $1 \%$. 
(C) 2020 UNU-WIDER. Published under a Creative Commons Attribution 4.0 International (CC BY 4.0) license.

Table 3: Average Peer Quality

\begin{tabular}{lccc}
\hline & $\begin{array}{c}\text { Full Sample } \\
(1)\end{array}$ & $\begin{array}{c}\text { Males } \\
(2)\end{array}$ & $\begin{array}{c}\text { Females } \\
(3)\end{array}$ \\
\hline Av. grade 12 score & $2.477^{* * *}$ & $2.461^{* * *}$ & $2.713^{* * *}$ \\
& $(0.244)$ & $(0.334)$ & $(0.369)$ \\
Observations & 2368 & 1043 & 1325 \\
& & & \\
Av. grade 10 score & $2.932^{* * *}$ & $2.597^{* * *}$ & $3.371^{* * *}$ \\
& $(0.291)$ & $(0.440)$ & $(0.422)$ \\
Observations & 2361 & 1041 & 1320 \\
\hline
\end{tabular}

Notes: This table reports instrumental variable estimates using the flexible second order polynomial described in the text. We control for mother's education, father's education, private school enrollment, age, income, and religion in all specifications (see notes in Table 1 for variable definitions). All regressions also include cutoff and month of survey fixed effects. Standard errors clustered at 0.25 bins of the centered high school exit exam score level are reported in parentheses. * significant at $10 \%,{ }^{*}$ significant at $5 \%,{ }^{* *}$ significant at $1 \%$. 
Review of Economics and Statistics Just Accepted MS.

https://doi.org/10.1162/rest_a_00966

(C) 2020 UNU-WIDER. Published under a Creative Commons Attribution 4.0 International (CC BY 4.0) license.

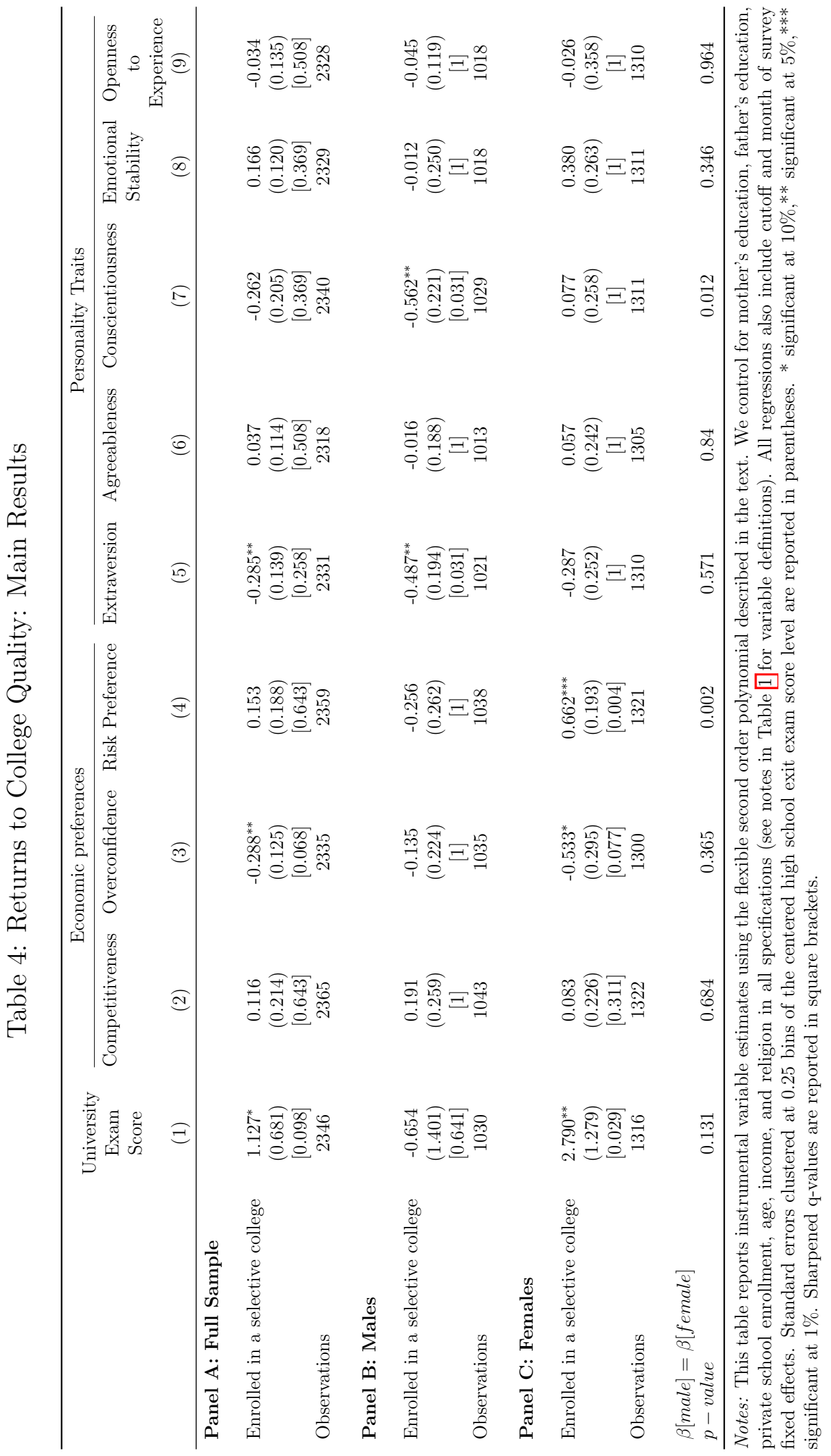


(C) 2020 UNU-WIDER. Published under a Creative Commons Attribution 4.0 International (CC BY 4.0) license.

Table 5: Pathways

\begin{tabular}{|c|c|c|c|c|c|}
\hline & \multicolumn{3}{|c|}{ Student Response } & \multicolumn{2}{|c|}{ Teachers } \\
\hline & $\begin{array}{c}\text { High } \\
\text { Attendance } \\
\text { (1) }\end{array}$ & $\begin{array}{l}\text { Relatively } \\
\text { Less } \\
\text { Attendance } \\
\quad(2)\end{array}$ & $\begin{array}{c}\text { External } \\
\text { Tutorial } \\
(3)\end{array}$ & $\begin{array}{c}\text { Class } \\
\text { Cancelled } \\
(4)\end{array}$ & $\begin{array}{c}\text { Student- } \\
\text { Teacher } \\
\text { Ratios } \\
(5)\end{array}$ \\
\hline Panel A: Males & & & & & \\
\hline Enrolled in a selective college & $\begin{array}{l}-0.128 \\
(0.086)\end{array}$ & $\begin{array}{c}0.322^{* * *} \\
(0.090)\end{array}$ & $\begin{array}{c}0.032 \\
(0.095)\end{array}$ & $\begin{array}{c}0.136 \\
(0.123)\end{array}$ & $\begin{array}{c}0.205 \\
(0.538)\end{array}$ \\
\hline Observations & 1043 & 1043 & 1043 & 1043 & 1043 \\
\hline Panel B: Females & & & & & \\
\hline Enrolled in a selective college & $\begin{array}{l}0.315^{\text {** }} \\
(0.126)\end{array}$ & $\begin{array}{l}-0.110 \\
(0.136)\end{array}$ & $\begin{array}{c}-0.018 \\
(0.108)\end{array}$ & $\begin{array}{c}0.019 \\
(0.150)\end{array}$ & $\begin{array}{l}-0.539 \\
(0.967)\end{array}$ \\
\hline Observations & 1325 & 1325 & 1325 & 1325 & 1325 \\
\hline
\end{tabular}

Notes: This table reports instrumental variable estimates using the flexible second order polynomial described in the text. We control for mother's education, father's education, private school enrollment, age, income, and religion in all specifications (see notes in Table 1 for variable definitions). All regressions also include cutoff and month of survey fixed effects. Standard errors clustered at 0.25 bins of the centered high school exit exam score level are reported in parentheses. * significant at $10 \%,{ }^{* *}$ significant at $5 \%,{ }^{* * *}$ significant at $1 \%$. 
Review of Economics and Statistics Just Accepted MS.

https://doi.org/10.1162/rest_a_00966

(C) 2020 UNU-WIDER. Published under a Creative Commons Attribution 4.0 International (CC BY 4.0) license.

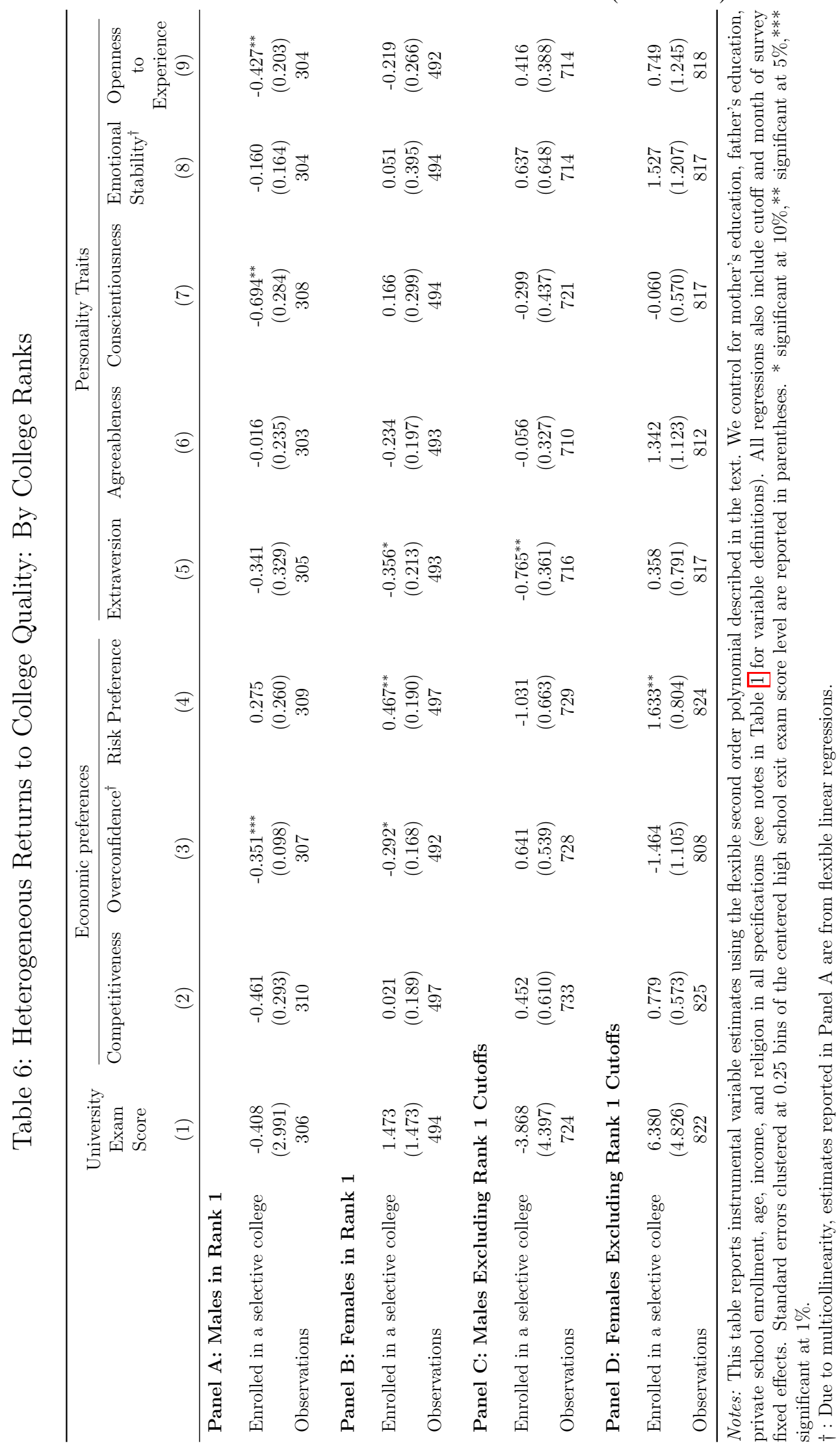

